\title{
What Happened? Are We Asking or Telling?
}

\author{
Marvin E. Kirsh
}

Kirsh2152000@yahoo.com

Department of Anthropology

California State University Los Angeles 


\begin{abstract}
A conceptual parallel is created between studies in anthropology and natural science. A space occupied by "the conceptualization" is argued to not only parallel symbolically the scientifically conceived value of volume as space, but to have an equal meaning- the spaces of the conceptual ordering of nature as manifestations of energy are held to be paralleling manifestations of the same energies that mold the environment. A growing historical asceticism attributed to the individual in struggles with nature and himself becomes destructive universally as the consequence of scientific activities that are focused from raw curiosities that are distant from real symbolic meaning.
\end{abstract}

\title{
Introduction
}

The anthropologist always approaches with the concern of what prints his own hands might leave on his subject of study and what changes they might effect. The imposition of change is more wished to fall within the domains of science and politics rather than anthropology. In the renditions of culture, nature, society and man anthropological theory makes prominent a distinction between itself and scientific conceptions of nature in which the latter does not sufficiently render a topic in which descriptions of evolution involve distributed traits that may occur temporally in any direction, towards living ancestors the present or future. It is argued that scientific endeavors modernly entail false conceptualizations of the natural world as a consequence of attempts to embody the temporal in grand schemes for explanation. Argument is 
proposed for a realistic view of science, criteria for adjustment to its' abstracted notions that is broader and less distinct from an anthropological perspective of the natural world. The means of a telling in description of 'what is' by the scientist, as he puts his explanation other than actual history into being, in presented.

\section{Results and Discussion}

Karl Marx (Tucker, 1978) in his writing, strictly found an internal consistency to make description as round and comprehendible in truth as one might impose upon the elements of descriptions of nature so that they would impart insight to nature. He drew on historical example to seal his descriptions with the truths he sought to communicate. Surfacing in the interface of readers in their relation to Marx's thoughts is not only Marx's assertive means of description, his force full opinions on the ideas and thoughts occurred to others in their public communications, but a conceptualization that associates experienced impulses of nature that imposed hardship to civilization, not only to communicated doctrine as best it elliptically embodied natural experience of the world, of nature, but, with impulse as the central feature, as it was delivered from Marx's hand as a symbol of the hand of man himself to the content of a doctrine so thoroughly contemplated to bear natural truth that men came to understand themselves as agents naturally licensed to employ impulse to effect change. It is not surprising that the communist manifesto not only became applied in attempts to mold politics and society in regions of the world that are considered less naturally hospitable and in need of correction, in places where excessive crime threatened the common good, where poverty was more pronounced, but came to be viewed in world areas where troubles from nature were not prominent, a more favorable climate existed, capitalism prevailed as a central 1 theme that 
endorsed an asceticism in the form of personal and economic investment into the molding of natural assets into machine like assemblies for production, but became known as the agent of an iron hand that imposed constrictions on the natural freedoms endowed to mankind-the iron hand of tyranny becoming associated not only with communism but with Marx's hand as it endorsed the free application of willed impulse. Marx's talented and genius rendition so compulsively seeking argument to align a truth of men and history with truths evident to nature failed, having evolved from the devoted recognition of the need to apply discipline to mens' steering of the courses of civilization into a disciplinary doctrine with which to convict either man or nature for offenses to the common good. It is obvious that neither the Western Societies or the conceived Communist states differed significantly with respect to the free willed application of impulse to elements of nature, either in the name of mild or severe disciplinary actions that reflected Marx's learned intellectual seeking, affection for balance as they are reflected in the stringency of his writing, depending on the nature of societies ultimately occurred, mostly as functions precipitated from the existing elemental conditions of nature peculiar to specific geographical regions.

From the perspective of the anthropologist this reduces to an aspect of culture in which Marx's reflections possess less than global insights sought for study, but historical description that is highly ordered conceptually, yet as an important body with which to make comparison with other cultures and their evolution. From a scientific perspective, these and other writings linger in vague fogs in which authors seek to reconcile notions of natural balance, biological homeostasis, as it might be envisioned to occupy spaces sociologically, politically and economically, find disappointment in the discovery that balances expected to occur naturally and to effect survival are not guaranteed in social evolution as a fact of the apriori existence of the 
individual and the species (Durkheim, 1997). There appears to be, in the evolution of culture, whether studied from a perspective of the economical, the political, the social, that the expectation of equilibrium as it occurs from companion oscillations and test, no existing topic with the title "balance", but more of a disappointing "being as it is" that is both condition dependent, and possessing "a going to" destination with no guarantee of improvement than is possessed in it " being as it is" or "was as it began". It is here that science "doesn't know" and cannot predict, is only a tool that is employed within the confounds of a terminology oriented with a connotation of "progress", but the term "progress" as it might be applied with respect to cultural meaning has come to have little meaning in a field that can encompass only comparison and the elaboration of differences from culture to culture, of the culture of the anthropologist, of the cultures of his acquaintance and studies, to the cultural studies of other anthropologists etc. Either scientific studies, by necessity of their quest for universal law, are naturally, innately not dependant on acquaintances that are location/position dependant, or have not evolved with a capacity to conceptualize general, holistic, law that is able to describe that which is conditionally dependant on environment and can yet encompasses a diversity of expression for that which is already thought elaborated theoretically and uniquely; social studies unable to accommodate the rigors of mathematical logic.

It is not uncontestable that the method and application of science works much like the described machinery of capitalism, in better analogy, like, the described machinery of an asceticism. Science involves a learned discipline in order to establish a principled objectivity that excludes the needs and individual specific symbols of the researcher. A parallel of the same divisions of universals and symbols in logical elaborations in the natural sciences and the divisions into criteria of need and symbolism in the social sciences is possible if it is shown that 
scientific objectivity, in its exclusion of language usages that refer nominally to the self, are not valid and that the practice of science entails the practice of an asceticism in the name of objectivity that is identical to the one that operates in capitalism.

The processes of science operate from a perspective that is first order with respect to the objects of perception; as if armed with a ruler and an electrically powered flashlight it is going to discern both the dimensions and means of operation, i.e. structure and function, via lines of cause and effect of those phenomenon operating from the world upon it that lend a comprehendible reality to sensually defined life experience. It has amassed a huge body of abstraction that today with the addition of notions of relativity have become possessed with sufficient confident to redefine the ruler it initially set off with in terms of the abstracted theory that proceeded from it. The constant velocity of light is given in the bureau of standards as a standard of distance for physical studies (Taylor et al, 2008 ) The concept of relative distance, though not an insignificant evolution, is not appropriately applied as it renders a meaning to reality that has become an assertion only by means of abstraction; the perceptual measuring tool employed, the ruler it uses is now an abstraction product of the abstractions made able by it, tangible footing is supplanted by the abstractions and hence mental processes as a new ruler (excuse the pun) to measure the universe, from which, upon meticulous, scrupulous observation and measurement with the original, relativity theory emerged. This action, not disputable, as a motion of willed impulse founded solely on an energetic interrogation to determine "what's happening" with which to order the universal cosmos emanating from inductive reasoning, bears, from strictly only the nature of the inducing agent (Kirsh, 2008), i.e. 
"a wish to understand" rather than an understanding in which it (a wish to understand) has necessity to exist also as an evolved component of the theory it has elaborated; its' inclusion is circumstantially shrugged for future discovery. Scientific pursuits are currently in progress with the wish to elaborate a physical model of the conscious mental process within the same abstracted structure.

This description put forth, may impress the universally inquisitive with associations parallel to a void, a null that effects man to resemble a still of ineffectuality with respect to the elements of nature, and urges that he must put forth also a comprehendible functioning of his will, willed endeavors within the same structure. It is perhaps not difficult to assert a need for self understanding in scientific terms and it is perhaps not difficult to contemplate to redirect inquiries framed with the, now, 'abstracted ruler" to inquiries labeled with the topics of symbolism and need, that themselves emerge reflexively as fingerprinting endeavors, the enumerations of identities of self with respect to the external that currently encompass both sociological and natural science studies.

Entailed to the topic of fingerprinting are questions of identity as they may be rendered in a multitude of ways, actual finger prints (i.e. of those of a man or women), unique, assumed to always yield the same consequences, the same nominal, individual as those of other methods such as genealogy, chromosome and gene constitution, physical traits, yet a common path of descent to connects these identifiers from a single source is hard to visualize but that they emerged together though appearing disconnected as separate identifying manifestations of the operations of structure and function that yield the unique identities of living entities. Yet, elaboration of the finger print of a rock or geological structure, or cloud formation, each 
conceived unique, categorized into species, as the products of enumeratable paths of emergence is not difficult to conceive of. At the boundary of aspects of mind and aspects of matter a rather dense cloud of confusion exists in which the topic of matter, as a matter of mind, has lead to a deceit motivated with the slogan "mind over matter" that is asserted topically, as object or subject, in which the descriptor "mind" bears at the same time both a same and different etiology from the topic of matter (Berkeley, 1982). The same null footing that accompanies the abstracted universal constant results, one is standing only on the ledges he constructed himself; one might abandon his pursuits at the popular slogan from Renee Descartes"I think therefore I am" (Cottingham, J et al, 1988). Why not? but to pursue description of 'what is', framed with respect to structure and function that does not penetrate 'the emergence' with research outlines seeking to explain time-i.e. in which time is omitted from the framing method (excuse the pun as men have proceeded to embody nature within abstracted 'frames' as a causing culprit of his sufferings) that includes only the coherent physical objects of perception and a contiguity that translates the emergence of one from the other by acquaintance or reasonably induced acquaintances with similarly knowable entities. One cannot weight a proton, a photon, hardly contemplate a mass but as weight, light but in contrast to its' absence, darkness for which a null concept of emptiness, the absolute vacuum might only be related to be strictly beyond the senses. The current mathematical study of relativity reduces to a study of identity-less-ness that might in common psychology reduce to the study of fear of not having an identity, a lighted mathematical reverse path to a state of non being. That such an abstracted endeavor is not the product of a labored and creative endeavor in which empirical test seems to validate abstraction is realistic, but communicated in a common psychological perspective would logically point more to a physical threat to the senses, to the being, rather than as a means of working of the 
universe against life that realistically is composed of the same elements-against elements that are composed of the same life. If man suffers of the elements he suffers of both himself and the elements; forgetting the wishes and abstracted symbols of mankind, the elements bear the suffering of both, the elements suffer.

A society of scientist and doctors might take note of this situation that calls for a better reasoning describable in the form of an asceticism not aimed towards the self, the individual, but as party with elements that are not construed to be composed of abstracted unique entities that are the products of self incentive and reductive reasoning, but whole heterogenosities as they are members of the perceivable kinds.

An ever present logic becomes apparent as a communicative function of entities that are construed to be strictly unique heterogeneous, each in unique spaces, to their finest divisions, less not to possess an identity at all. In this manner notions of a deity are again makeable as an abstracted concept based on the inherited same inherited proximities that both form nature and our acquired concepts of it that arise from the continuum of those also present in external nature; second that both the arrangements of cognitive concepts as a sorting of inherited proximities of concepts and new experience are associated together as a manifestation of structure and function based emergence, as a mutual becoming in which the only existing divisions between the inert and the animate, the inanimate and the animate, mind and matter are from the proximities and associations that existed prior, all having the same attributes as that also of mind, as a way in which the world proceeds.

It is in this sense that when the scientist counts with a ruler, and the sociologists accumulates a number for distinct traits that each unity becomes multiplied by numbers in the mind of the 
scientist that reflect, project abstractly into accounting what is identity-less , external, feared non being. Mathematical volumes of external space given symbolic meaning that is translated into squares and cube figures with coordinates on graphing paper can possess in the mind not only the symbolisms of volumes occupied by the structured, acquired and found orders of the external, but if concepts emerge in a synchrony with the physical volumes of the elements as they are arrived from experience, representing themselves to the psyche, volumes represented to the psyche, are also represented in, and from within the psyche, encompassing symbolically if not comprising a material actuality to the universe and all of its divisions physically, internally and externally The environment has been ordered incorrectly, multiplied in an unsorted manner many fold to include, with thoughts of objectivity in mind, multiple volumes of objects that are each present each only once when properly sorted with established pertinent relationships to the self. The "concept' itself might find its' way to symbolic representation as an entity of space, represented as an unwitnessible difference between witnessible or symbolically conceived witnessible volumes It is forgotten that the volume, a cubic space, only a model of real space, obviously represents a perceived process involving emergence, energy, synergisms that are the consequence of combination and recombination, is the breath of life itself making record of its' existence.

In the Michelson Morley experiment (Michaelson, 1886, 1887) to measure the velocity of light a meaning for results must involve the witness pair man and light. What meaning is currently assumed for it but as an observed phenomenon of the universe. A specific relation to the self, mankind, survival is not considered, its' characterization not only perceived as significant, made as a standard with which to judge the environment but without an elaboration 
of meaning with respect to survival. The relation man-light cannot be extended to the relationship for instance of dog-light, grass in the back yard-light though the perceived light maybe common to all relationships : its' metabolism, the tissues and surfaces, the entities involved are different in each set, each set and its survival criteria are different from one another. It cannot be dismissed that the morphology and physiologies of tissues all have some conceptual relationships that not only have some commonalities but differences that are pronounced in cases. Light, construed to be a universal source of energy for living entities might obviously also be that which it is the funding energy for the spaces occupied by living entities and thus the volume perceived light occupies might be construed to possess a lifetime value in relation to the life time, as a mathematical ratio of the life time of perceiving entities to its' own, if it is the same entity of light of which the species is derived, funds its' maintenance and or continued emergence. Thus its relation to tissue volumes, surface areas and divisions, energies maintaining divisions as entity specific ratios rather than absolutes is its only priority, yet the physics of light is lended an entirely different conceptual space. What other occupation might men be consuming, in the study of light but what might be associated with their survival?

It is in this sense that men blindly measure what reflects conceptual analogy to a potential darkness that remains as an undifferentiated entity in pursuits. Second, it is not necessarily matter of fact to assume that modern civilization pursues this course of mathematical studies of processes and change involving entities that are not proximal conceptually necessarily as the matter of fact sole possible course of civilization. In the primitive societies of distant Africa native symbolisms are difficulty accommodated into the cultural experience of anthropologists (Fortes and Evans-Pritchard, 1940). Global change to their orders is not conceived by them under conditions of revolution, only replacement to what exists; symbolisms and needs never 
become redefined by abstractions to cause and effect, i.e. -"what is supposed to have really caused the problem." Perhaps as they are viewed as living out unchanged the same symbolisms, modern man is not aware of doing the same in a living out of a material/physical impulse occurred if not continuing, an acceleration/change from which he emerged in the course of his

evolution. In contrast to a basically statically behaving experienced nature in older societies his response is to a naturally occurred disturbance that has him, unrestfully, testing nature with abstracted impulses, unaware or unable to finger what is extrapolated to be a projected universal character, wholeness of nature, but is a push he had or does receive that is made into study as a null identityless for comparison., simultaneously finding that he is able work nature with his abstractions to make a less suffering existence, but is also unawarely making ploy, feeding the same Achilles heel that may had lead to unrealized better happenstances,

\section{Conclusion}

What's happening (excuse the pun) is more of a self willed acceleration to what happened. In almost all of the economic, and social occupations of today a struggle for survival, for personal room, entails a science and technology that consumes space in a wholesale manner as if it were a functionally separate ,matter from the personal spaces of mind and the environment, as infinite as the universe can be conceived to be large in size, but abstractly not filled with heterogeneous entities such as the self, society and the perceivable world, but possessed with a null emptiness symbolized from his own fears of non-being. In contrast symbolism, considered primitive, is strictly filled in many older societies with being, animate gods, physical entities in contrast to a deity conceived mostly as living abstractions that, in contrast, do not occupy perceptual but conceptual spaces; spaces when made as symbols of science rather than belief, 
both become victim when in the absence of real knowledge or sound questioning of their content and origins, the past ascent of man (Kirsh, 2009). 


\section{References}

Berkeley, George, (1982)A Treatise Concerning the Principles of Human Knowledge, Hackett Pub Co Inc.

Durkheim, Emile, (1997) The Division of Labor in Society The Free Press, New York N.Y.

Cottingham, J., Stoothoff, R., Kenny, A., and Murdoch, D., trans. (1988). The Philosophical Writings Of Descartes in 3 vols. Cambridge University Press.

Fortes, Meyer, Evans-Pritchard, Edward Evan, (1940) Introduction [African political Systems], in Erickson, Paul, A., Murphy, Liam. D., (2006) Readings for a History of Anthropological Theory second edition Broadview Press Ontario, Canada

Kirsh, Marvin, E ,(2008) Induction Space and Positive Ethics, Ludus Vitalis, vol. XVI, num. 30, 2008, pp. 225-228

Kirsh, Marvin, E.,(2009) Anthropology and Parallelism: The Individual as a Universal, International Journal of Sociology and Anthropology Vol. 1(7) pp. 112-115, November, 2009

Available online http://www.academicjournals.org/ijsa

Taylor, Barry, N. Thompson, Ambler, eds (2008) The International System of Units sect 2.1.1.1 (pae 23) NIST Special Publication 3302008 Edition

Michaelson, A., Morley, E., (1886), Influence of the Motion of the Medium on theVelocity of Light Am. J. of Science 3 1:377-386

Michaelson, A., Morley, E., (1887), On the Relative Motion of the Earth and the Luminiferous Ether Am. J. of Science, 34:333-336

Tucker, Robert C. Ed. (1978) The Marx-Engels Reader W. W. Norton Inc. New York, NY 10110 
